\title{
MELTBLOWING: MULTIPLE POLYMER JETS AND FIBER-SIZE DISTRIBUTION AND LAY-DOWN PATTERNS
}

\author{
A. L. Yarin ${ }^{* 1,2}$, S. Sinha-Ray ${ }^{1}$, B. Pourdeyhimi ${ }^{3}$ \\ ${ }^{1}$ Department of Mechanical and Industrial Engineering, \\ University of Illinois at Chicago, \\ 842 W. Taylor St., Chicago IL 60607-7022 \\ ${ }^{2}$ Center for Smart Interfaces, Technische Universität Darmstadt \\ Petersenstr. 32, 64287 Darmstadt, Germany \\ ${ }^{3} 3427$ The Nonwovens Institute, Box 8301, \\ North Carolina State University \\ Raleigh NC 27695-8301
}

\begin{abstract}
In this work a comprehensive model of three-dimensional configurations of polymer jets in meltblowing from die exit to deposition screen is developed. In addition, multiple jets were modeled simultaneously, as well as deposition on a screen moving normally to the principal jet direction was accounted for. All important properties of polymer melts are used in the simulations, namely density, zero-shear viscosity and the viscoelastic relaxation time. In addition, the material parameters responsible for the temperaturedependent variation of the material properties are used. All the other parameters are the
\end{abstract}


operational parameters characterizing gas flow. The results include prediction of the fiber deposition patterns and fiber-size distributions in the resulting nonwovens. The angular distributions in lay-down nonwovens are also predicted. Comparisons with the experimental data suggest that the model captures main trends rather accurately.

\section{Introduction}

Meltblowing is one of the most popular methods of producing various micro-denier nonwovens [1-3]. In this method polymer melt (or polymer solution) is issued through a die nosepiece into a high speed subsonic coaxial air jet. The air jet pulls the polymer jet, dramatically accelerates and stretches it, a vigorous bending and flapping take place, which additionally stretch the polymer jet. The gas jet is submerged in surrounding atmosphere at room temperature. As a result, it is cooling down, as well as cools down the polymer jet inside. The latter solidifies at some distance from the die exit and is deposited as a nonwoven onto a grid-like screen moving normally to the unperturbed jet direction. Each individual jet forms a fiber in the nonwoven matrix, with fiber diameters typically being in the range of $2-10 \mu \mathrm{m}$, albeit submicron or several hundred micron fibers were also reported. The screen is typically made of metal and moves with a speed of the order of 1-20 m/s. It is moving over a chamber connected to a vacuum pump to prevent air motion along the screen.

The basic theory of meltblowing was outlined in the recent works $[4,5]$ where planar bending of a polymeric viscoelastic liquid jet in a high speed gas flow was described in detail. Both isothermal and non-isothermal situations were studied. However, only a single jet was considered and deposition onto a screen was disregarded. 
Without accounting for the presence of multiple jets and their deposition onto a screen, such practically important questions as fiber-size distribution in the nonwoven and deposition patters cannot be addressed. The latter are the main aim of the present work.

Section II describes our theoretical results for the straight parts of meltblown polymer jets and compares them to the available experimental data. Section III describes the results for meltblowing of multiple non-isothermal polymer jets and discusses the results in comparison with the available experimental data. Conclusions are drawn in section IV. The theoretical framework for the three-dimensional bending of polymer jets in meltblowing is presented in the Appendix.

\section{The initial straight part of the jet}

The present section modifies the previous results of [4] to make them appropriate for the description of the initial part of real jets in meltblowing, which will be used as a subroutine in the general numerical code for simulations of multiple three-dimensional nonisothermal polymer jets depositing onto a moving substrate. In real meltblowing processes polymer jets are issued from dies in a nosepiece at a relatively low speed of about $10 \mathrm{~cm} / \mathrm{s}$. They are issued into concentric gas jets with velocities of the order of 100-250 m/s. As a result, polymer jets experience a tremendous pulling force at their initial part (of the order of $1 \mathrm{~mm}$ from the die) and rapidly accelerate. The concentric gas

jets are formed by oblique impingement of several gas jets surrounding a polymer jet, which produces a significant circular force sustaining straight configuration of the initial part of the latter. In addition, polymer jets at the initial part are still sufficiently thick and possess a significant bending stiffness, which precludes any bending, similarly to the 
situation encountered in electrospinning [6]. It is emphasized that over such a short distance the velocity of the concentric submerged gas jet practically does not fade due to viscous interaction with the surrounding air and will be assumed to be constant in the present section.

The stretching aerodynamic drag force per unit jet length $\mathrm{q}_{\tau}$ is described similarly to Refs. 4 and 5 as

$$
\mathrm{q}_{\tau}(\mathrm{x})=\mathrm{C} \pi \mathrm{a} \rho_{\mathrm{g}}\left(\mathrm{U}_{\mathrm{g}}-\mathrm{V}_{\tau}\right)^{2}\left[\frac{2 \mathrm{U}_{\mathrm{g}}-\mathrm{V}_{\tau} \mathrm{a}}{v_{\mathrm{g}}}\right]^{-0.81}
$$

In Eq. (3), $\mathrm{x}$ is the axial coordinate reckoned from the die exit, $\mathrm{f}(\mathrm{x})=\pi \mathrm{a}^{2}$ and $\mathrm{a}(\mathrm{x})$ are the cross-sectional area and radius, respectively, $\mathrm{V}_{\tau}(\mathrm{x})$ is the absolute axial velocity of the polymer jet, $\mathrm{U}_{\mathrm{g}}(\mathrm{x})$ is the absolute velocity of the concentric gas jet, and $\rho_{\mathrm{g}}$ and $v_{\mathrm{g}}$ are the gas density and kinematic viscosity, respectively.

Equation (1) is, in fact, empirically based and stems from the experiments, in which a wire or filament were pulled parallel to itself through stagnant air, as described in [7] and references therein. It was used in [4] with the pre-factor established in the above-mentioned work, $\mathrm{C}=0.65$. While the general structure of Eq. (1) is physically sound, the modeling in [5] demonstrated that this value is probably underestimated and should be increased, since otherwise it is impossible to achieve a proper pulling force to stretch viscoelastic polymeric jets. The underestimation of the value of $\mathrm{C}$ in the experiments described in [7] and references therein, most probably, has deep physical roots. Indeed, the situation where a wire is pulled through stagnant air with a certain speed is not equivalent to the situation where a non-moving wire (or a jet, as in meltblowing) is subjected to parallel gas flow with the same speed, since in the latter case 
turbulent eddy viscosity is expected to be higher and thus the drag force, and thus $\mathrm{C}$, should be higher. An additional circumstance which points out at an additional increase in the value of $\mathrm{C}$ is related to the fact that in the experiments where it was established velocities never approached levels characteristic of meltblowing, so sufficiently high turbulence levels were not reached. Due to all these circumstances, while keeping the general structure of Eq. (1) with no change, the value of $\mathrm{C}$ was increased to $\mathrm{C}=100$, which was validated a posteriori by the comparison with the experimental data for meltblowing as described below.

The quasi-one-dimensional continuity and momentum balance equations for the straight part of meltblown viscoelastic polymer jets given in [4] were solved numerically using Eq. (1) for the pulling force. Similarly to [4], the upper-convected Maxwell model (UCM) was used as an appropriate rheological constitutive model for viscoelastic polymeric liquids in such strong elongational flows as in meltblown jets. As a result, distributions of the cross-sectional radius $\mathrm{a}(\mathrm{x})$, longitudinal velocity $\mathrm{V}_{\tau}(\mathrm{x})$, the longitudinal and radial deviatoric stresses $\tau_{\mathrm{xx}}$ and $\tau_{\mathrm{yy}}$ and the stress $\sigma_{\mathrm{xx}}=\tau_{\mathrm{xx}}-\tau_{\mathrm{yy}}$ in the jet cross-section are found. As in [4], the equations were rendered dimensionless by the following scales: $V_{\tau 0}$ for $V_{\tau}$ and $U_{g}$, the distance of the initial straight part $L_{\text {straight }}$ for $\mathrm{x}, \mathrm{a}_{0}$ for a, $\mu_{0} / \theta_{0}$ (with $\mu_{0}$ and $\theta_{0}$ being the viscosity and relaxation time of polymeric liquid at the die temperature $\mathrm{T}_{0}$ ) for deviatoric stresses, where the subscript 0 corresponds to the die exit where the radius and velocity values are assumed to be given. The dimensionless groups involved in the simulations are given by

$$
\mathrm{R}=\frac{\rho_{\mathrm{g}}}{\rho}, \quad \ell=\frac{\mathrm{L}_{\text {straight }}}{\mathrm{a}_{0}}, \quad \mathrm{Re}=\frac{2 \mathrm{~V}_{\tau 0} \mathrm{a}_{0}}{\mathrm{v}_{\mathrm{g}}}, \quad \mathrm{De}=\frac{\theta_{0} \mathrm{~V}_{\tau 0}}{\mathrm{~L}_{\text {straight }}}
$$


with Re and De being the Reynolds and Deborah numbers, respectively, with the secondary dimensionless groups being

$$
\mathrm{E}=\frac{2 \mathrm{R}}{\operatorname{De} \ell \operatorname{Re} M}, \quad \mathrm{M}=\frac{\mu_{\mathrm{g}}}{\mu_{0}}
$$

In Eq. (3) $\mu_{\mathrm{g}}$ denotes gas viscosity.

In the simulations of the initial straight part of the jet the following parameter values corresponding to real practical meltblowing conditions were used. In a typical meltblowing process the polymer throughput through every die in a nosepiece of a radius of the order of $100 \mu \mathrm{m}$, is of the order of $0.3-1.0 \mathrm{~g} / \mathrm{min}$, which means that $\mathrm{V}_{\tau 0} \approx 0.17-0.5 \mathrm{~m} / \mathrm{s}$. The typical value of gas velocity is of the order of $150 \mathrm{~m} / \mathrm{s}$. Using this data, the value of the dimensionless gas velocity $\mathrm{U}_{\mathrm{g}} / \mathrm{V}_{\tau 0}$ was taken in the experiment as 390 , whereas the value of $\operatorname{Re}$ used was $R e=7.5$. The initial length scale of the straight part $\mathrm{L}_{\text {straight }}$ is of the order of $1 \mathrm{~mm}$, which makes $\ell=10$. The relaxation time $\theta_{0}$ is of the order of $10^{-2} \mathrm{~s}$, which might be expected for strong elongational processes, where the leading physical mechanism of relaxation will be associated with the recoil of stretched macromolecular coils $[8,9]$. Then, a reasonable value of the Deborah number De was taken as $\mathrm{De}=1.59$. Following [4], the values of $\mathrm{M}$ and $\mathrm{R}$ both were taken to be $0.001 \mathrm{~A}$ sufficiently long die channel allows longitudinal elastic stresses acquired in the flow inside to relax. Therefore, the value of the longitudinal deviatoric stress $\tau_{\mathrm{xx} 0}$ was taken to be as low as $\tau_{\mathrm{xx} 0}=0.0001$, which corresponds to the dimensional value of $0.00025 \mathrm{~N} / \mathrm{m}^{2}$. It was found that any further decrease in the value of $\tau_{\mathrm{xx} 0}$ does not affect the results.

The predicted distributions of the jet radius and velocity, as well as of the longitudinal deviatoric stress are plotted in Figs. 1a-c. As expected, the values of the 
radial deviatoric stress are practically immaterial compared to $\tau_{\mathrm{xx}}$, the result similar to that of [4], and thus not shown here.

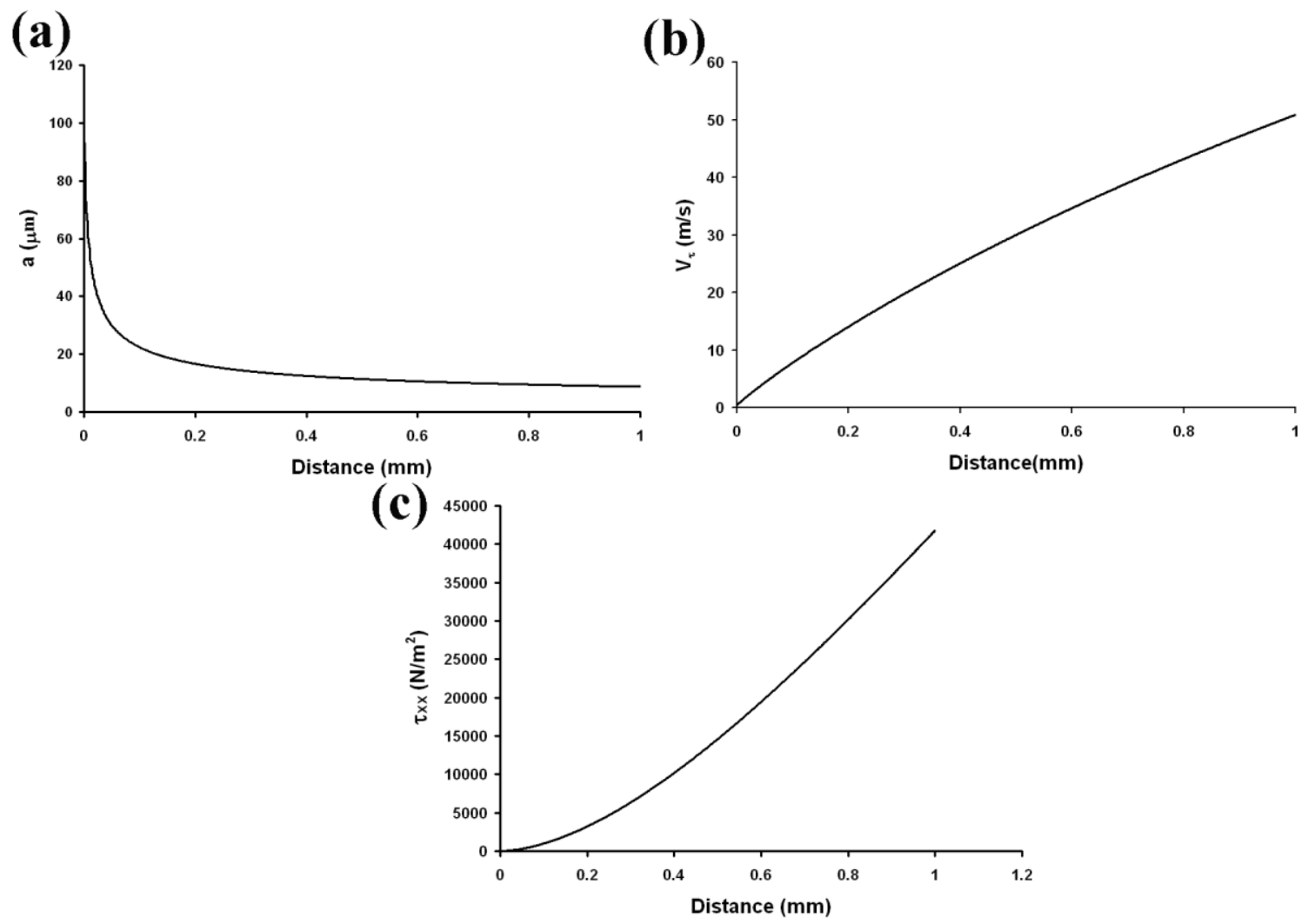

FIG. 1. Distributions of (a) dimensionless cross-sectional radius, (b) axial velocity and (c) longitudinal deviatoric stress along the polymer jet.

Figure 1a shows that the value of the dimensionless radius at the end becomes 8.75 $\mu \mathrm{m}$. The figure demonstrates that an abrupt decrease in the cross-sectional radius happens close to the exit from a die. Figure $1 \mathrm{~b}$ demonstrates that at the end of the straight part of the polymer jet its velocity is already about $30 \%$ of the velocity of the surrounding gas jet. In comparison, mention that the experimental data of [10] show that at a distance of about $5 \mathrm{~mm}$ from the die the velocity of the meltblown polymer jet had already been increased up to $43 \%$ of the velocity of the surrounding gas jet, which is the level 
comparable with our numerical prediction. A more detailed comparison with the experimental data [10] is, unfortunately, impossible due to the lack of a number of crucial input parameters characterizing the experimental situation, as well as an insufficient number of the experimental points available. In addition, it can be mentioned that the experimental data of [11] show that at the die to collector distance (DCD) of $6 \mathrm{~mm}$ the fiber diameter was $49 \mu \mathrm{m}$ at the blowing speed of $123.2 \mathrm{~m} / \mathrm{s}$, whereas at the DCD of 7 $\mathrm{mm}$ the fiber diameter was $117 \mu \mathrm{m}$. These values are about 5-10 times higher than our prediction of $8.75 \mu \mathrm{m}$. However, the difference can be attributed to the following factors: (a) the lack of the detailed rheological data for the polymer melt blown in [11]; (b) the unspecified differences in the operating conditions; (c) the as-formed fibers were deposited on a screen in [11], which allows the fibers to relax and increase their crosssectional size, which was not considered by the theory in this section. Nevertheless, the trend observed in the experiments of [11] and the numerical predictions show that there was a significant decrease in fiber diameter already at a distance of about $1 \mathrm{~mm}$ from the die.

Note also, that Fig. 1c shows that at the end of the straight part of the polymer jet quite significant longitudinal stress has already been reached, which can be attributed to the strong stretching in the initial part of the jet.

The conditions at the end of the initial straight part of the jet will be taken as the initial conditions for the bending part, which begins from there on and is described in the following section.

\section{Bending part of the jet}


After the straight part of the jet becomes sufficiently thin, its bending stiffness becomes very small (since it is proportional to $\mathrm{a}^{4}$ ) and small bending perturbations which are imposed on the jet, begin to grow. The description of the bending part of the jet is based on the general momentless quasi-one-dimensional equations of the dynamics of free liquids jets $[5,8]$. In distinction from [5], in the present section we deal not with planar bending of the jet but rather with the fully three-dimensional bending, and the details are given in the Appendix.

In a typical meltblowing process the die to collector distance (DCD) L is of the order of $10-15 \mathrm{~cm}$ and $\mathrm{U}_{\mathrm{g} 0}$ is of the order of $150 \mathrm{~cm} / \mathrm{s}$, and at the operating temperature $\mathrm{T}_{0}=250-350^{0} \mathrm{C}$ the shear viscosity of the polymer melt is within the range $5-20 \mathrm{~g} /(\mathrm{cm} \mathrm{s})$. Using these values, the Reynolds number $\operatorname{Re}_{1}=\rho L U_{\mathrm{g} 0} / \mu_{0}$ is of the order of 40000 . In the simulations described below, the value of Re was taken as 46000 .

At the end of the straight part of the jet the cross-sectional radius was found to be $8.75 \mu \mathrm{m}$ (cf. section II). This makes the value of $\operatorname{Re}_{\mathrm{a}}=2 \mathrm{a}_{0} \mathrm{U}_{\mathrm{g} 0} / v_{\mathrm{g}}=174$.

The value of the factor $\mathrm{C}$ in the expression for the pulling force in Eq. (14) in the Appendix was taken as $\mathrm{C}=14$ instead of $\mathrm{C}=100$ used in the calculations for the straight part of the jet in section II. Such reduction in the value of $\mathrm{C}$ can be interpreted as the accounting for the fact that jet pulling by air becomes additionally less effective when the jet is inclined relative to the gas flow due to bending.

The relaxation time $\theta_{0}=0.1 \mathrm{~s}$ was used in the calculations for the bending part instead of $\theta_{0}=0.01 \mathrm{~s}$ used in the calculations for the straight part in section II. This corresponds to the fact that the strongest stretching happens in the straight part of the jet, and thus, the fastest relaxation processes are expected there $[8,9]$. In the case of a weaker 
stretching corresponding to the bending part, even the reptational relaxation mode $[8,9]$ can play role. The corresponding value of $\mathrm{De}_{0}$ was taken as $\mathrm{De}_{0}=400$. The effect of gravity was neglected, which corresponds to the Froude number $\mathrm{Fr}=\infty$ (cf. the Appendix). In addition, it was taken $\mathrm{K}=0.25$, where $\mathrm{K}=\mathrm{c}_{\mathrm{pg}} / \mathrm{c}$ is the ratio of the specific heat at constant pressure for gas to the specific heat for polymer melt.

The simulations were done with 62 jets. Each jet was excited by the cumulative effect of the turbulent eddies described using Eqs. (35) and (36) in the Appendix with the frequencies $\Omega_{\mathrm{j}}$ chosen according to the following formula: $\Omega_{\mathrm{j}}=\Omega^{0} \mathrm{p}_{\mathrm{j}}$, where $\mathrm{p}_{\mathrm{j}}$ are random numbers from the interval $[0,1]$ generated anew at each time step and initiated by a current time of the computer clock, i.e. non-repeatable.

The basic variants were simulated at the value of $\Omega^{0}=0.3$ (according to [5]). For comparison, simulations were also done with $\Omega^{0}=0.1$ and 0.5 .

The value of the stress $\tau_{\tau \tau 0}$ for Eq. (36) in the Appendix is found from the value of $\tau_{\mathrm{xx}, \text { end,straight }}$ calculated in section II. Due to the different scales used for nondimensionalization in sections II and III (see the Appendix), they are related as $\tau_{\tau \tau 0}=$ $\tau_{\mathrm{xx}, \text { end straight }} / \mathrm{De}_{0}$, which made $\tau_{\tau \tau 0}=41.84$

In addition, the following values were used as in [5]: $\mathrm{T}_{\mathrm{g} \infty}=0.5, \mathrm{~J}=10^{-3}$ and $\ell=10^{3}$ and $\mathrm{U}_{\mathrm{A}}=10$ (see the Appendix for the definitions). Also, the simulation of the turbulent gas jet was done according to [12] and is briefly described in the Appendix.

The deposition screen was located at $\xi=1$, normal to the direction of blowing and could be moved in the $\mathrm{Z}$ direction with a given velocity $\mathrm{V}_{\text {screen }}$ from $0.015-0.15$ (rendered dimensionless by $\mathrm{U}_{\mathrm{g} 0}$ ), which corresponds to the dimensional range of $2.25 \mathrm{~m} / \mathrm{s}$ to 22.5 $\mathrm{m} / \mathrm{s}$, which is of practical interest. The choice of the collector screen velocity range also 
aims at the elucidation of its effect on the radius distribution, stretching of the nonwoven lay-down and pattern formation. The jet deposition on the screen was implemented in the following way: at the moment the free end of the jet had reached the screen, its $\xi$ and $\mathrm{H}$ coordinates were frozen, whereas its $Z$ coordinate could vary in accordance with the translational motion of the screen in the $\mathrm{Z}$ direction. The cross-sectional radius of each jet at the moment it touched the screen was also frozen and used to produce jet-size distributions discussed below. The jet-size distributions were recorded at five different dimensionless time moments $\mathrm{t}=45,60,65,70$ and 75 , which correspond to $0.03 \mathrm{~s}, 0.04 \mathrm{~s}$, $0.043 \mathrm{~s}, 0.047 \mathrm{~s}$ and $0.05 \mathrm{~s}$, respectively, for Figs. 3 and 5. The jet configurations at $\mathrm{t}=75$ corresponding to $0.05 \mathrm{~s}$ are shown in Figs. 2 and 4 for different values of the screen velocity. For the sake of brevity, the radius distribution and jet evolution are illustrated only for $\Omega^{0}=0.3$. In addition, a detailed comparison of the maximum fiber diameter, mean fiber diameter, standard deviation and the number of jets reaching the collecting screen for different values of its velocity and $\Omega^{0}$ is given in Table 1 for two dimensionless time moments $\mathrm{t}=45$ and 75 . 


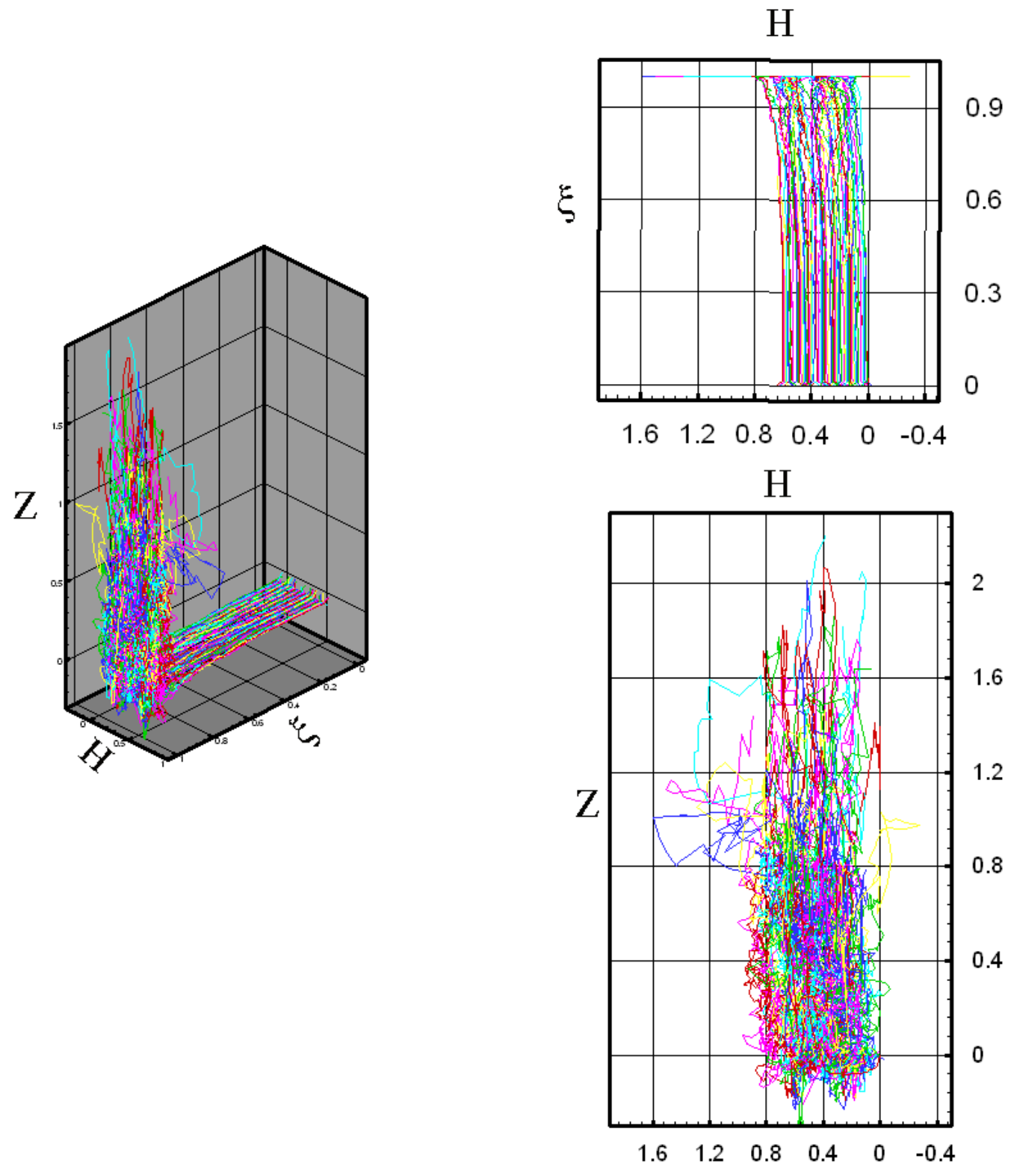

FIG. 2. Jet configurations in the case of the dimensionless screen velocity $\mathrm{V}_{\text {screen }}=0.015$ (which corresponds to $2.25 \mathrm{~m} / \mathrm{s}$ ) at $\mathrm{t}=75$ (which corresponds to $0.05 \mathrm{~s}$ ) for $\Omega^{0}=0.3$. 
(a)

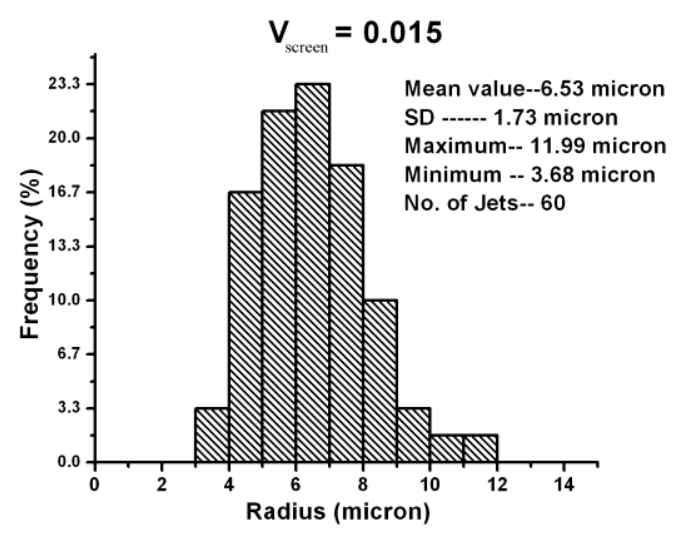

(c)

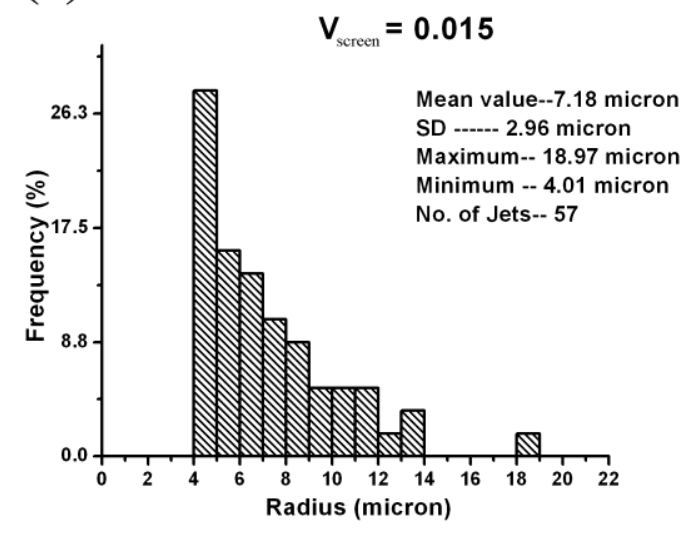

(b)

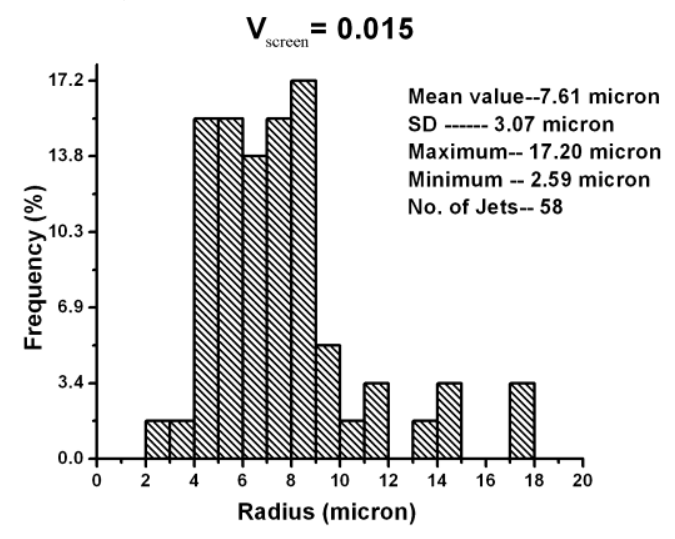

(d)

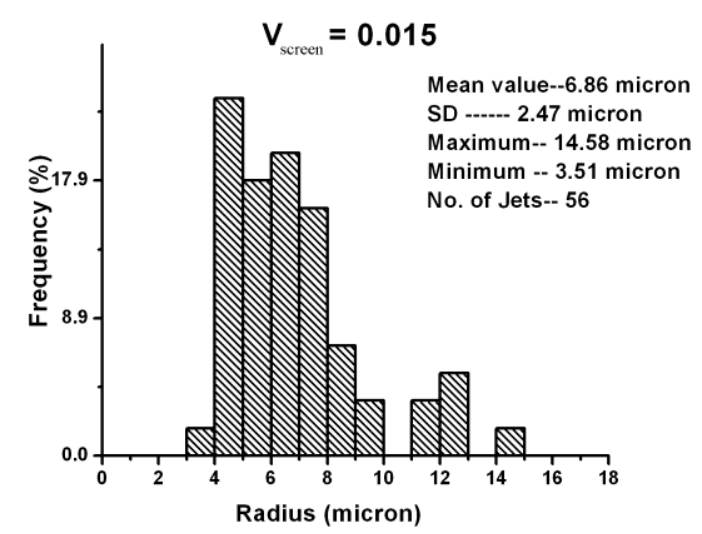

(e)

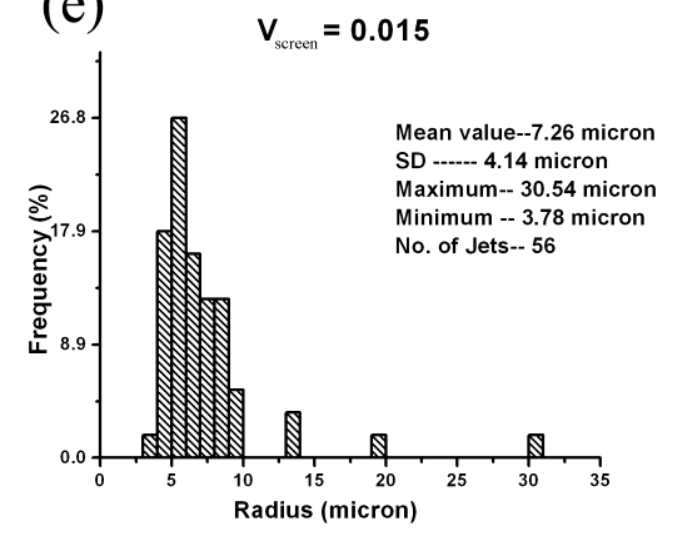

FIG. 3. Predicted radius distributions for the screen velocity $\mathrm{V}_{\text {screen }}=0.015(2.25 \mathrm{~m} / \mathrm{s})$ at the time moments (a) t=45 (0.03 s), (b) 60 (0.04 s), (c) 65 (0.043 s), (d) 70 (0.047 s), (e) $75(0.05 \mathrm{~s})$ for $\Omega^{0}=0.3$. 


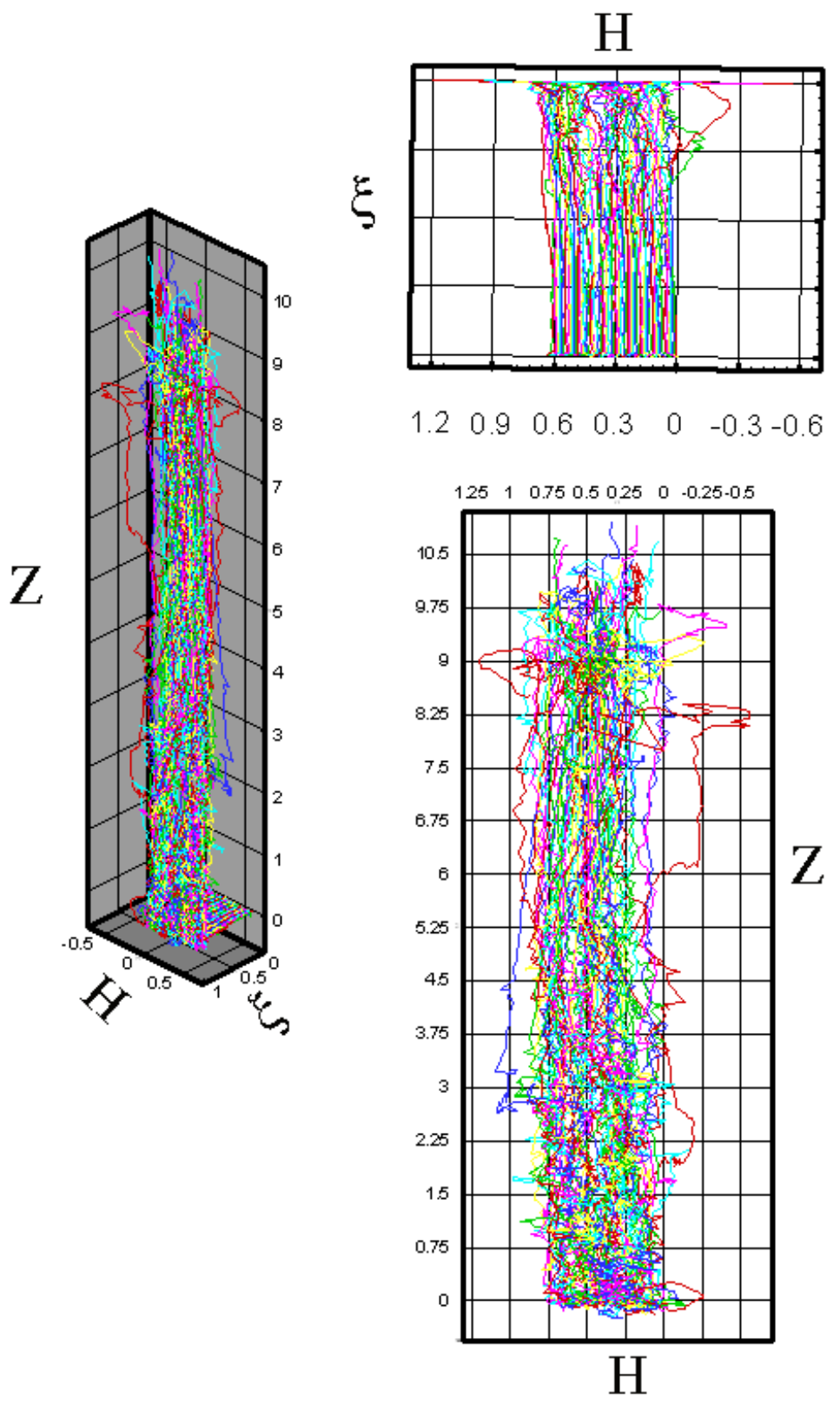

FIG. 4. Jet configurations in the case of the dimensionless screen velocity $\mathrm{V}_{\text {screen }}=0.15$ (which corresponds to $22.5 \mathrm{~m} / \mathrm{s}$ ) at $\mathrm{t}=75$ (which corresponds to $0.05 \mathrm{~s}$ ) for $\Omega^{0}=0.3$. 

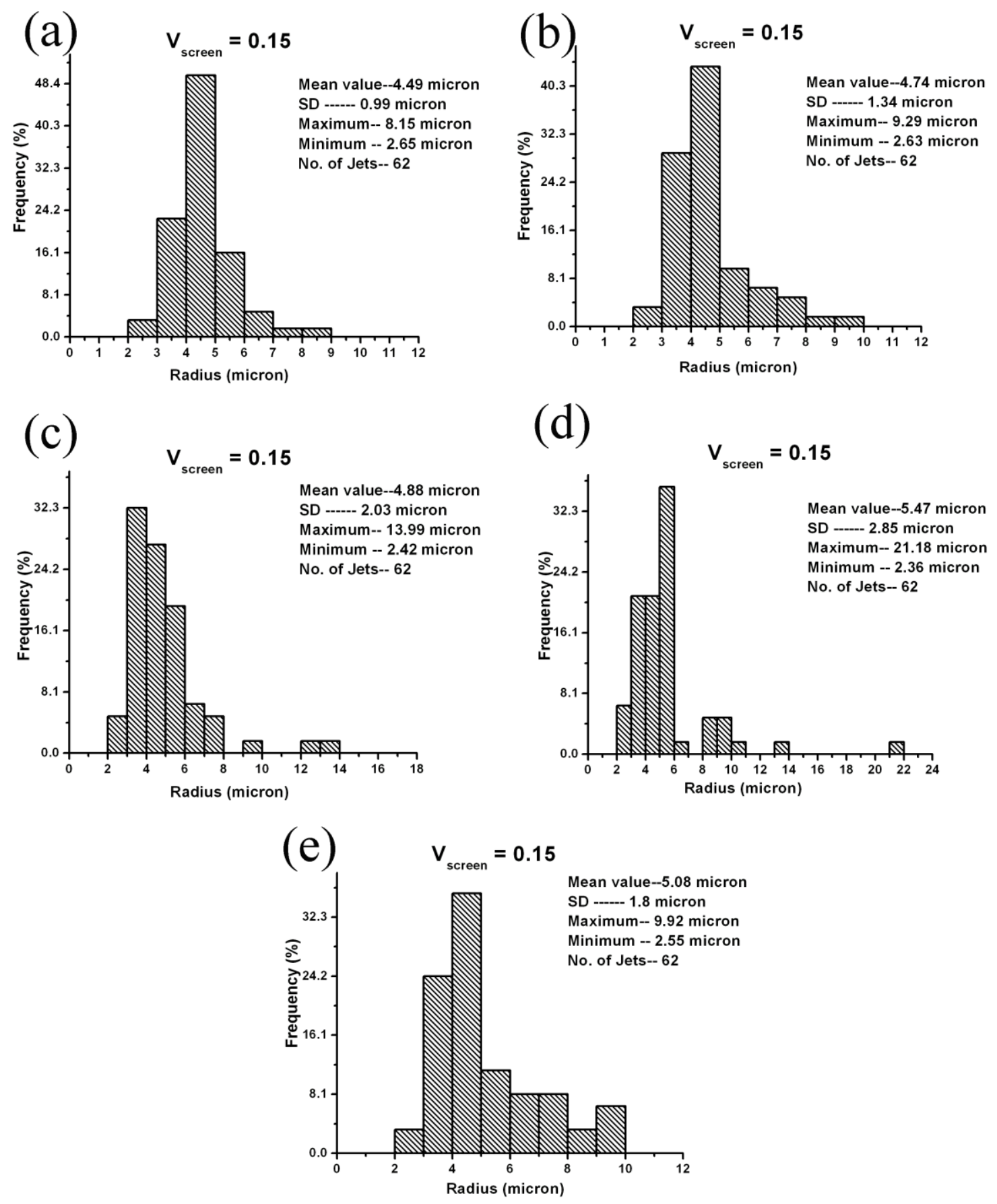

FIG. 5. Predicted radius distributions for the screen velocity $V_{\text {screen }}=0.15(22.5 \mathrm{~m} / \mathrm{s})$ at the time moments (a) t=45 (0.03 s), (b) 60 (0.04 s), (c) 65 (0.043 s), (d) 70 (0.047 s), (e) 75 $(0.05 \mathrm{~s})$ for $\Omega^{0}=0.3$. 


\begin{tabular}{|c|c|c|c|c|c|c|}
\hline$\Omega^{0}$ & $\mathbf{V}_{\text {screen }}$ & $\begin{array}{c}\text { Time } \\
\text { moment }\end{array}$ & $\begin{array}{l}\text { Max fiber } \\
\text { diameter } \\
\text { in } \mu \mathrm{m}\end{array}$ & $\begin{array}{l}\text { Mean fiber } \\
\text { diameter } \\
\text { in } \mu \mathrm{m}\end{array}$ & $\underset{\text { in } \mu \mathrm{m}}{\text { SD }}$ & $\begin{array}{l}\text { Number of } \\
\text { jets reaching } \\
\text { the collecting } \\
\text { screen }\end{array}$ \\
\hline \multirow{10}{*}{0.1} & \multirow{2}{*}{0.015} & 45 & 27.8 & 14.14 & 4.96 & 58 \\
\hline & & 75 & 26.9 & 13.76 & 4.9 & 55 \\
\hline & \multirow[t]{2}{*}{0.03} & 45 & 85.44 & 15.02 & 10.86 & 60 \\
\hline & & 75 & 29.04 & 12.18 & 4.54 & 56 \\
\hline & \multirow{2}{*}{0.06} & 45 & 37.8 & 13.04 & 6.84 & 62 \\
\hline & & 75 & 24.8 & 10.98 & 3.74 & 61 \\
\hline & \multirow{2}{*}{0.10} & 45 & 33.10 & 12.34 & 5.86 & 62 \\
\hline & & 75 & 27.50 & 10.50 & 3.30 & 62 \\
\hline & \multirow{2}{*}{0.15} & 45 & 53.14 & 11.34 & 6.94 & 62 \\
\hline & & 75 & 27.56 & 9.2 & 3.00 & 62 \\
\hline \multirow{10}{*}{0.3} & \multirow[t]{2}{*}{0.015} & 45 & 23.98 & 13.06 & 3.46 & 60 \\
\hline & & 75 & 61.08 & 14.52 & 8.28 & 56 \\
\hline & \multirow{2}{*}{0.03} & 45 & 21.80 & 11.58 & 3.06 & 60 \\
\hline & & 75 & 24.68 & 12.66 & 3.38 & 58 \\
\hline & \multirow[t]{2}{*}{0.06} & 45 & 22.14 & 10.42 & 3.12 & 62 \\
\hline & & 75 & 57.18 & 11.46 & 6.64 & 62 \\
\hline & \multirow{2}{*}{0.10} & 45 & 25.06 & 10.28 & 3.78 & 62 \\
\hline & & 75 & 24.24 & 10.8 & 4.08 & 62 \\
\hline & \multirow[t]{2}{*}{0.15} & 45 & 16.30 & 8.98 & 1.98 & 62 \\
\hline & & 75 & 19.84 & 10.16 & 3.6 & 62 \\
\hline \multirow{10}{*}{0.5} & \multirow{2}{*}{0.015} & 45 & 29.84 & 12.34 & 4.26 & 62 \\
\hline & & 75 & 35.2 & 13.8 & 5.38 & 62 \\
\hline & \multirow[t]{2}{*}{0.03} & 45 & 53.14 & 11.34 & 6.94 & 62 \\
\hline & & 75 & 28.50 & 13.14 & 6.64 & 62 \\
\hline & \multirow{2}{*}{0.06} & 45 & 27.16 & 10.50 & 3.92 & 62 \\
\hline & & 75 & 25.14 & 11.96 & 3.82 & 62 \\
\hline & \multirow[t]{2}{*}{0.10} & 45 & 31.04 & 10.24 & 3.88 & 62 \\
\hline & & 75 & 34.56 & 10.92 & 4.70 & 62 \\
\hline & \multirow[t]{2}{*}{0.15} & 45 & 17.94 & 9.48 & 2.68 & 62 \\
\hline & & 75 & 25 & 11.02 & 4.36 & 62 \\
\hline
\end{tabular}


Table 1. The numerically predicted maximum fiber diameter, mean fiber diameter, standard deviation (SD) and the number of jets reaching the collecting screen for different values of $\Omega^{0}$. The results for several values of the screen velocity are shown at two dimensionless time moments $\mathrm{t}=45$ and 75 .

The experimental data on meltblowing in [13] reveal that for a DCD of $22 \mathrm{~cm}$ the maximum and mean fiber diameters of $35 \mu \mathrm{m}$ and $18.3 \mu \mathrm{m}$, respectively, for a research line. For a commercial line, [13] reports the maximum and mean fiber diameters of 19 $\mu \mathrm{m}$ and $7.5 \mu \mathrm{m}$, respectively. In comparison, Table 1 shows that our numerically predicted values of the maximum fiber diameter are within the range of 17.94- $40 \mu \mathrm{m}$ in reasonable agreement with the experimental data. The experimental data in [11] for polypropylene $\left(M_{w}=175000\right.$ and $\left.M_{n}=32000\right)$ show that the mean value of the fiber diameter was $6 \mu \mathrm{m}$ with a standard deviation (SD) of $3 \mu \mathrm{m}$, and for polypropylene with a different molecular weight $\left(M_{w}=120000\right.$ and $\left.M_{n}=30000\right)$ it was $5 \pm 2 \mu \mathrm{m}$. In addition, our numerical results listed in Table 1 show that the predicted mean fiber diameter is in the range of 8.98-14.52 $\mu \mathrm{m}$ with the range of SD from 1.98 to $10.86 \mu \mathrm{m}$. These predictions are in a rather good agreement with the experimental data. It is emphasized that Refs. 11 and 13 lack many details needed for detailed characterization of the polymer melts and governing parameters used (e.g. the rheological behavior, the initial temperature, polymer flow rate, collector speed, collecting technique, etc.), therefore the comparison with these data is inevitably conditional.

In spite of the above-mentioned uncertainty, the experimental data $[11,13]$ were used for comparison with our numerical predictions in Fig. 6. It can be seen that in spite 
of the above-mentioned uncertainties in the exact experimental conditions, the numerical results are in qualitative agreement with the experimental data.

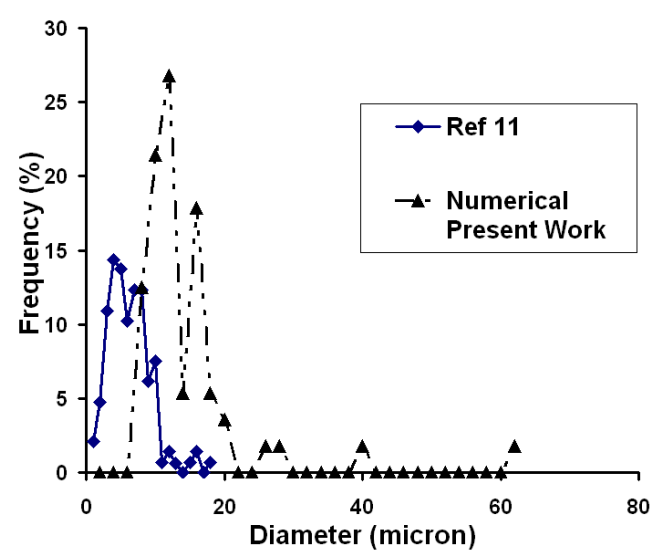

(a)

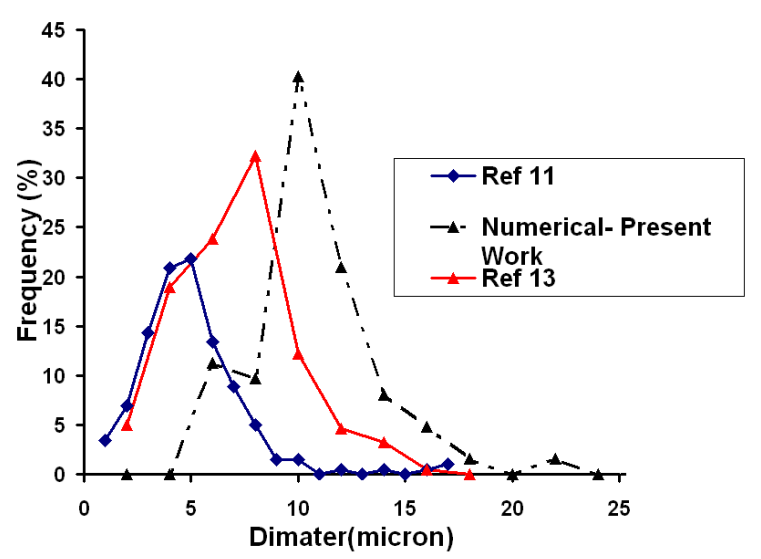

(b)

FIG. 6. Comparison of the experimental and numerically predicted radius distributions.

The numerical results correspond to $\Omega^{0}=0.3$. In panel (a) $\mathrm{V}_{\text {screen }}=0.015$, in (b) $\mathrm{V}_{\text {screen }}=0.06$.

Figures 3 and 5 and Table 1 show that the values of the basic frequency $\Omega^{0}$ and screen velocity $\mathrm{V}_{\text {screen }}$ do not affect significantly the values of the mean fiber diameter. In regards of the effect of these two parameters, no visible trends was found according to the numerical results. As is evident from Figs. 3 and 5 , at $\Omega^{0}=0.3$ the radius distributions appear to be approaching the normal distribution as the screen velocity $\mathrm{V}_{\text {screen }}$ increases. A similar approach to the normal distribution at higher values of $\mathrm{V}_{\text {screen }}$ was observed at the other values of $\Omega^{0}$ (not shown here).

It is emphasized that the numerical results listed in Table 1 show that a few jets from the initial 62 did not arrive at the collection screen in some cases. At a certain 
moment of time the cross-sectional radius of those few jets became zero at a certain cross-section. This manifests cohesive jet breakup and probably corresponds to the socalled fly formation. The observed cohesive jet breakup is more pronounced at $\Omega^{0}=0.1$ than at higher values of $\Omega^{0}$. Still, the maximum number of broken jets which did not reach the screen was not more than 7 at $\Omega^{0}=0.1$.

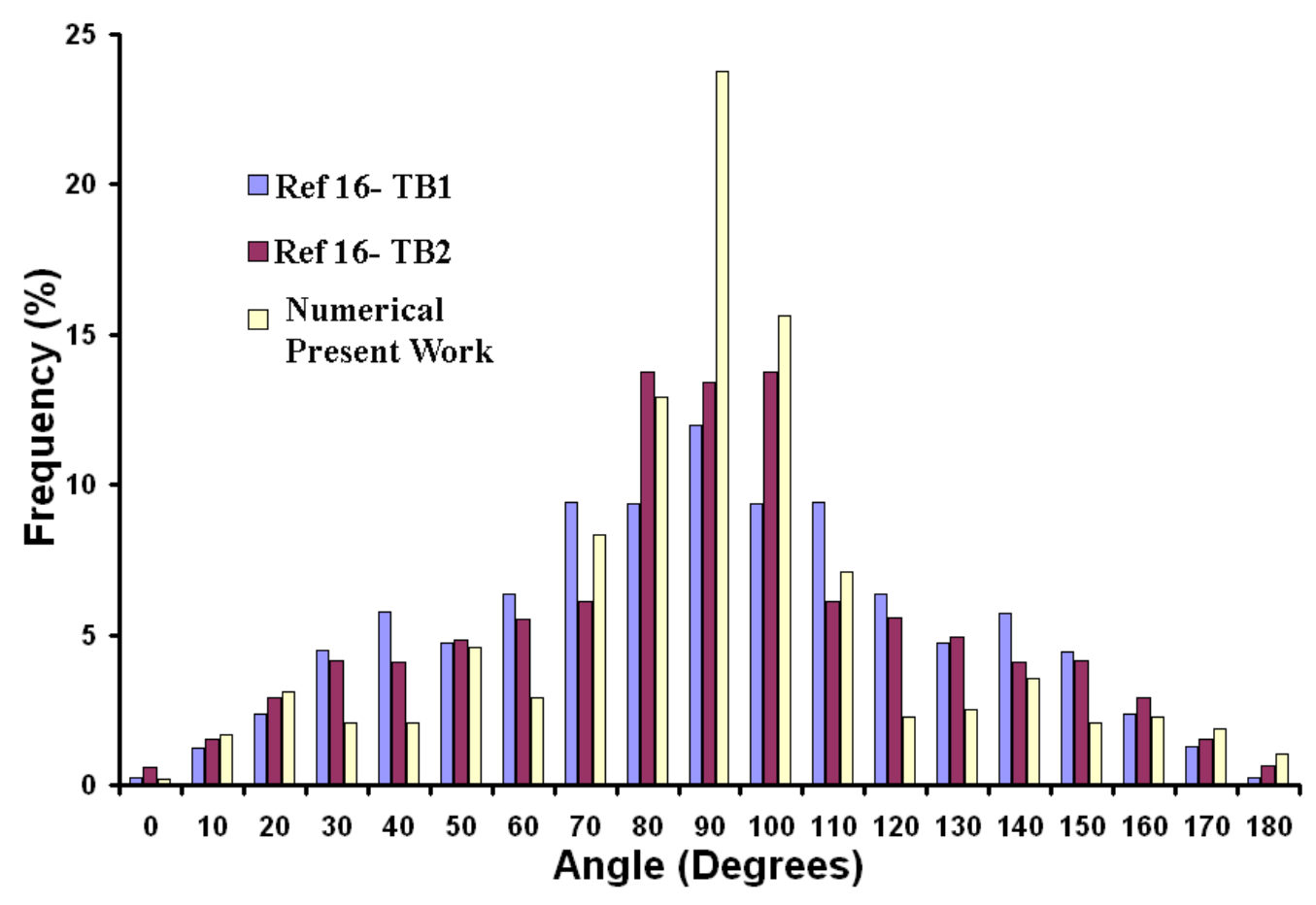

FIG. 7. Comparison of the predicted fiber orientation distribution with the experimental data [14]. TB1 and TB2 denote two different grades of polyester nonwoven structures meltblown in [14].

The angular distribution in the fiber lay-down on the collecting screen predicted by the present method for a distance of $2 \mathrm{~cm}$ from the first touchdown point of the polymer jets in the direction of the collector screen motion is compared to the experimental data [14] in Fig. 7. In this particular case the relaxation time value of $\theta_{0}=0.025 \mathrm{~s}$ was used 
which corresponds to the Deborah number $\mathrm{De}_{0}=100$. It is emphasized that in [14] the velocity of the collector screen was not reported. Therefore, in the simulations it was taken as in [15] as $30 \mathrm{~m} / \mathrm{min}$ (which corresponds to the dimensionless value of 0.0033 ). Note that in [14], in the lay-down nonwoven $0^{0}$ corresponded to the machine direction. In the present work, however, the machine direction corresponds to $90^{\circ}$, and the data of [14] was transformed accordingly. Figure 7 shown that the numerical predictions slightly overestimate fiber orientation in the machine direction, albeit in general show a pattern similar to the experimental one.

\section{Conclusion}

The comprehensive quasi-one-dimensional model of the dynamics of threedimensional excursions of polymer jets in meltblowing outlined in the present work and implemented with 62 jets was used to simulate a number of characteristic cases and compare the results with the available experimental data. The results obtained revealed the following. The model is capable of predicting reasonable patterns of fiber deposition in nonwovens formed on a moving screen, as well as the fiber-size distributions for different operation conditions. The predicted values of the mean fiber diameter and its standard deviations were found to be in a fairly good agreement with the experimental data from literature, even though the experimental reports do not specify rheological behavior of polymer solutions, as well as a detailed pattern of the initial interaction of gas and polymer jets. It was also found that the model reveals both bimodal and normal types of fiber-size distributions in nonwovens in qualitative agreement with the experimental data. The numerical predictions also suggest that the effect of the turbulence spectrum in 
gas flow, as well as the screen speed, do not affect significantly the values of the mean diameter of deposited fibers, since no visible trend was found. It was also predicted that the fiber-size distribution approaches the normal one as the screen velocity increases. The numerical results also demonstrated cohesive breakup of several jets before they reach the screen, which might be kindred to the so-called fly formation. The predicted angular fiber distributions in lay-down nonwovens qualitatively resemble those observed experimentally.

The comprehensive model of this work elevates the theoretical/numerical capabilities for meltblowing modeling to the level previously achieved in modeling of electrospinning in $[6,16,17]$.

\section{Acknowledgment}

The current work is supported by the Nonwovens Cooperative Research Center (NCRC).

\section{Appendix}

The governing equations read $[4,5,8]$

$$
\begin{aligned}
& \frac{\partial \lambda \mathrm{f}}{\partial \mathrm{t}}+\frac{\partial \mathrm{fW}}{\partial \mathrm{s}}=0 \\
& \frac{\partial \lambda \mathrm{fV}}{\partial \mathrm{t}}+\frac{\partial \mathrm{fWV}}{\partial \mathrm{s}}=\frac{1}{\rho} \frac{\partial \mathrm{P} \tau}{\partial \mathrm{s}}+\lambda \mathrm{fg}+\frac{\lambda}{\rho} \mathbf{q}_{\text {total }}
\end{aligned}
$$

where Eq. (2) expresses the mass balance (the continuity equation) and Eq. (3) the momentum balance. Note that continuity and momentum balance equations for a straight jet (in section II) follow from the general Eqs. (2) and (3). 
In Eqs. (2) and (3) $t$ is time, $s$ is an arbitrary parameter (coordinate) reckoned along the jet axis, $\mathrm{f}(\mathrm{s}, \mathrm{t})=\pi \mathrm{a}^{2}$ is the cross-sectional area [the cross-section is assumed to stay circular even in bending jets-a valid approximation according to Refs. 5 and 8; a(s,t) denotes its radius], $\mathrm{W}$ is the liquid velocity along the jet relative to a cross-section with a certain value of $\mathrm{s}$, the stretching factor $\lambda=|\partial \mathbf{R} / \partial \mathrm{s}|$, where $\mathbf{R}(\mathrm{s}, \mathrm{t})$ is the position vector of the jet axis, $\mathbf{V}(\mathrm{s}, \mathrm{t})$ is the absolute liquid velocity in the jet, $\rho$ is liquid density, $\mathrm{P}(\mathrm{s}, \mathrm{t})$ the magnitude of the longitudinal internal force of viscoelastic origin in the jet cross-section, $\boldsymbol{\tau}$ is the unit tangent vector of the jet axis, $\mathbf{g}$ gravity acceleration and $\mathbf{q}_{\text {total }}$ is the overall aerodynamic force imposed on unit jet length by the surrounding gas. Boldfaced characters here and hereinafter denote vectors. $P(s, t)$ can be expressed as $f\left(\tau_{\tau \tau}-\tau_{n n}\right)$, where $\tau_{\tau \tau}$ and $\tau_{\mathrm{nn}}$ are the longitudinal and normal deviatoric stresses in the jet crosssection, respectively. In case of strong stretching and in meltblown jets, in particular, one can expect that the inequality $\tau_{\tau \tau}>>\tau_{n n}$, holds (cf. section II), and thus $P=f \tau_{\tau \tau}$.

Let $s$ be a Lagrangian parameter of liquid elements in the jet (e.g. their initial Cartesian coordinate along the blowing direction). Then, $\mathrm{W}=0$, since the particles keep their Lagrangian coordinate unchanged, and Eq. (2) after integration reduces to

$$
\lambda \mathrm{a}^{2}=\lambda_{0, \text { straight }} \mathrm{a}_{0, \text { straight }}^{2}
$$

where subscript 0 ,straight denotes the values corresponding to the end of the straight part of the jet predicted in section II.

The local projections of the momentum balance equation (3) on the tangent, normal and binormal to the jet axis, after several minor terms are omitted for simplicity, read

$$
\frac{\partial \mathrm{V}_{\tau}}{\partial \mathrm{t}}=\frac{1}{\rho \mathrm{f} \lambda} \frac{\partial \tau_{\tau \tau} \mathrm{f}}{\partial \mathrm{s}}+\mathrm{g}_{\tau}+\frac{\mathrm{q}_{\text {total }, \tau}}{\rho \mathrm{f}}
$$


$\frac{\partial \mathrm{V}_{\mathrm{n}}}{\partial \mathrm{t}}=\frac{\mathrm{k} \tau_{\tau \tau}}{\rho}+\mathrm{g}_{\mathrm{n}}+\frac{\mathrm{q}_{\mathrm{total}, \mathrm{n}}}{\rho \mathrm{f}}$

$\frac{\partial \mathrm{V}_{\mathrm{b}}}{\partial \mathrm{t}}=\mathrm{g}_{\mathrm{b}}+\frac{\mathrm{q}_{\text {total }, \mathrm{b}}}{\rho \mathrm{f}}$

where $\mathrm{k}$ is the local curvature of the jet axis and subscripts $\tau, \mathrm{n}$ and $\mathrm{b}$ denote the projections on the directions of the local unit tangent, normal and binormal, $\boldsymbol{\tau}, \mathbf{n}$ and $\mathbf{b}$, respectively.

The position vector $\mathbf{R}(\mathrm{s}, \mathrm{t})$ and the corresponding stretching ratio $\lambda(\mathrm{s}, \mathrm{t})$ are expressed as

$$
\begin{aligned}
& \mathbf{R}(\mathrm{s}, \mathrm{t})=\mathbf{i} \xi(\mathrm{s}, \mathrm{t})+\mathbf{j} \mathrm{H}(\mathrm{s}, \mathrm{t})+\mathbf{k Z}(\mathrm{s}, \mathrm{t}) \\
& \lambda=\left|\frac{\partial \mathbf{R}}{\partial \mathrm{s}}\right|=\xi_{, \mathrm{s}}^{2}+\mathrm{H}_{, \mathrm{s}}^{2}+\mathrm{Z}_{, \mathrm{s}}^{2}{ }^{1 / 2}
\end{aligned}
$$

where $\xi, \mathrm{H}$ and $\mathrm{Z}$ denote projections of the position vector on the laboratory Cartesian frame with the unit vector $\mathbf{i}$ corresponding to the direction of blowing and $\mathbf{j}$ and $\mathbf{k}$ the other two unit vectors.

The local curvature of the jet axis corresponding to the position vector of Eq. (8) is

$$
\mathrm{k}=\frac{\sqrt{\mathrm{Z}_{\mathrm{ss}} \mathrm{H}_{, \mathrm{s}}-\mathrm{H}_{\mathrm{ss}} \mathrm{Z}_{\mathrm{s}}{ }^{2}+\xi_{, \mathrm{ss}} \mathrm{Z}_{\mathrm{s}}-\mathrm{Z}_{\mathrm{ss}} \xi_{, \mathrm{s}}{ }^{2}+\mathrm{H}_{, \mathrm{ss}} \xi_{, \mathrm{s}}-\xi_{, \mathrm{ss}} \mathrm{H}_{, \mathrm{s}}{ }^{2}}}{\lambda^{3}}
$$

Each $\mathrm{s}$ in the subscript corresponds to differentiation in the s direction.

The velocity components are related with the rate of the jet axis evolution according to the following kinematic relations

$$
\begin{aligned}
& \mathrm{V}_{\mathrm{n}}=\mathrm{n}_{\xi} \frac{\partial \xi}{\partial \mathrm{t}}+\mathrm{n}_{\eta} \frac{\partial \mathrm{H}}{\partial \mathrm{t}}+\mathrm{n}_{\zeta} \frac{\partial \mathrm{Z}}{\partial \mathrm{t}} \\
& \mathrm{V}_{\mathrm{b}}=\mathrm{b}_{\xi} \frac{\partial \xi}{\partial \mathrm{t}}+\mathrm{b}_{\eta} \frac{\partial \mathrm{H}}{\partial \mathrm{t}}+\mathrm{b}_{\zeta} \frac{\partial \mathrm{Z}}{\partial \mathrm{t}}
\end{aligned}
$$


$\mathrm{V}_{\tau}=\tau_{\xi} \frac{\partial \xi}{\partial \mathrm{t}}+\tau_{\eta} \frac{\partial \mathrm{H}}{\partial \mathrm{t}}+\tau_{\zeta} \frac{\partial \mathrm{Z}}{\partial \mathrm{t}}$

The aerodynamic force [5] $\mathbf{q}_{\text {total, }}$, which consists of the normal (bending) component, and the drag force, as well as the longitudinal pulling component is given by the following expression

$$
\begin{aligned}
& \mathbf{q}_{\text {total }}=-\rho_{\mathrm{g}} \mathrm{U}_{\mathrm{g}}^{2} \mathrm{fkn}+\rho_{\mathrm{g}} \mathrm{U}_{\mathrm{g}}^{2} \mathrm{an}_{\xi}^{2} \operatorname{sign}\left(\mathrm{n}_{\xi}\right) \mathbf{n}+ \\
& \mathrm{C} \pi \mathrm{a} \rho_{\mathrm{g}} \mathrm{U}_{\mathrm{g}} \tau_{\xi}-\mathrm{V}_{\tau}{ }^{2}\left[\frac{2 \mathrm{a} \mathrm{U}_{\mathrm{g}} \tau_{\xi}-\mathrm{V}_{\tau}}{v_{\mathrm{g}}}\right]^{-0.81} \tau
\end{aligned}
$$

where $U_{g}$ is the absolute local velocity of the surrounding gas jet, which is given by [5] as $\mathrm{U}_{\mathrm{g}}(\xi, \mathrm{H})=\mathrm{U}_{\mathrm{g} 0} \varphi(\xi, \mathrm{H})$

In equation (15) $\mathrm{U}_{\mathrm{g} 0}$ is the gas velocity at the die exit and the dimensionless function $\varphi(\xi, \mathrm{H})$ is given by $[5,12]$ as

$$
\varphi(\xi, H)=\frac{4.8 / \ell}{\xi+4.8 / \ell} \frac{1}{1+\zeta^{2} / 8}{ }^{2}, \quad \zeta=\zeta(\xi, H)=\frac{H}{0.05 \xi+4.8 / \ell}
$$

In Eq. (16) $\xi$ and $\mathrm{H}$ are rendered dimensionless by L, the distance between the end of the straight part of the jet and the deposition screen, and $\ell$ is given by $\mathrm{L} / \mathrm{a}_{0, \text { straight }}$.

For the constitutive equation for the longitudinal deviatoric stress similarly to section II the upper-convected Maxwell model (UCM) is used

$$
\frac{\partial \tau_{\tau \tau}}{\partial \mathrm{t}}=2 \tau_{\tau \tau} \frac{1}{\lambda} \frac{\partial \lambda}{\partial \mathrm{t}}+2 \frac{\mu}{\theta} \frac{1}{\lambda} \frac{\partial \lambda}{\partial \mathrm{t}}-\frac{\tau_{\tau \tau}}{\theta}
$$

In the long bending part of the jet, variation of the rheological constitutive parameters with the decrease in temperature $\mathrm{T}$ is felt and described using the following expressions for the viscosity $\mu$ and relaxation time $\theta$ similarly to [5] 
$\mu=\mu_{0} \exp \left[\frac{\mathrm{U}}{\mathrm{R}}\left(\frac{1}{\mathrm{~T}}-\frac{1}{\mathrm{~T}_{0}}\right)\right], \quad \theta=\theta_{0} \frac{\mathrm{T}_{0}}{\mathrm{~T}} \exp \left[\frac{\mathrm{U}}{\mathrm{R}}\left(\frac{1}{\mathrm{~T}}-\frac{1}{\mathrm{~T}_{0}}\right)\right]$

where $\mathrm{T}_{0}$ is the melt and gas jet temperature at the end of the straight part, which is practically the same as at the die exit, $\mu_{0}$ and $\theta_{0}$ are the corresponding values of the viscosity and relaxation time, $\mathrm{U}$ is the activation energy of viscous flow and $\mathrm{R}$ is the absolute gas constant.

The thermal balance equation for a jet element reads

$$
\frac{\partial}{\partial \mathrm{t}} \rho \mathrm{cTf} \lambda=-\mathrm{h} \quad \mathrm{T}-\mathrm{T}_{\mathrm{g}} 2 \pi \mathrm{a} \lambda
$$

where $\mathrm{c}$ is the specific heat, $\mathrm{h}$ is the heat transfer coefficient and $\mathrm{T}_{\mathrm{g}}$ the local gas temperature.

The governing equations are rendered dimensionless using the following scales: $U_{\mathrm{g} 0}$ for all the velocities, $\mathrm{a}_{0 \text {,straight }}$ for $\mathrm{a}, \mathrm{a}_{0, \text { straight }}^{2}$ for $\mathrm{f}, \mathrm{L} / \mathrm{U}_{\mathrm{g} 0}$ for $\mathrm{t}, \rho_{\mathrm{g}} \mathrm{U}_{\mathrm{g} 0}^{2} \mathrm{a}_{0 \text {,straight }}$ for $\mathbf{q}_{\text {total }}$, $\mu_{0} \mathrm{U}_{\mathrm{g} 0} / \mathrm{L}$ for all the stresses, $\mathrm{L}$ for all other lengths except radius. As a result, Eq. (19) takes the form

$$
\frac{\partial \mathrm{T}}{\partial \mathrm{t}}=-2 \mathrm{Nu} \ell \frac{\mathrm{JK}}{\operatorname{Re}_{\mathrm{a}} \operatorname{Pr}_{\mathrm{g}}} \frac{\lambda}{\lambda_{0}} \mathrm{~T}-\mathrm{T}_{\mathrm{g}}
$$

where $\operatorname{Pr}_{\mathrm{g}}$ is the molecular Prandtl number for gas, $\mathrm{K}=\mathrm{c}_{\mathrm{pg}} / \mathrm{c}$ is the ratio of the specific heat at constant pressure for gas to the specific heat for polymer melt, and the Nusselt number $\mathrm{Nu}=\left(\mathrm{h} 2 \mathrm{a} / \mathrm{k}_{\mathrm{g}}\right)$, with $\mathrm{k}_{\mathrm{g}}$ being the molecular thermal conductivity of gas, is given by the following expression [5]

$$
\mathrm{Nu}=0.495 \mathrm{Re}_{\mathrm{a}}{ }^{1 / 3} \operatorname{Pr}_{\mathrm{g}}{ }^{1 / 2}
$$

Substituting Eq. (18) into Eq. (17) and using Eq. (20), we arrive at the following equation 


$$
\frac{\partial \Phi}{\partial \mathrm{t}}=-\frac{2 \mathrm{Nu} \ell \mathrm{JK}}{\operatorname{Re}_{\mathrm{a}} \operatorname{Pr}_{\mathrm{g}} \operatorname{De}_{0} \lambda_{0}} \frac{\mathrm{T}-\mathrm{T}_{\mathrm{g}}}{\lambda}-\mathrm{T} \exp \left[-\mathrm{U}_{\mathrm{A}}\left(\frac{1}{\mathrm{~T}}-1\right)\right] \frac{\tau_{\tau \tau}}{\mathrm{De}_{0} \lambda^{2}}
$$

with $\Phi=\tau_{\tau \tau}+\mathrm{T} / \mathrm{De}_{0} / \lambda^{2}$ and the following two dimensionless groups involved

$$
\mathrm{De}_{0}=\frac{\theta_{0} \mathrm{U}_{\mathrm{go}}}{\mathrm{L}}, \quad \mathrm{U}_{\mathrm{A}}=\frac{\mathrm{U}}{\mathrm{RT}_{0}}
$$

where $\mathrm{De}_{0}$ is the Deborah number.

Using the theory of the axisymmetric turbulent gas jets [12], the temperature field in the gas jet is given by the following expression

$$
\mathrm{T}_{\mathrm{g}}(\xi, \mathrm{H})=\mathrm{T}_{\mathrm{g} \infty}+\frac{\operatorname{Pr}_{\mathrm{t}}+1 / 2}{0.05 \sqrt{6}} \frac{1-\mathrm{T}_{\mathrm{g} \infty}}{\ell} \frac{1}{\xi+4.8 / \ell} \frac{1}{1+\zeta^{2} / 8^{2 \mathrm{Pr}_{\mathrm{i}}}}
$$

where $T_{g \infty}$ is the surrounding cold gas temperature far from the polymer jet rendered dimensionless by $\mathrm{T}_{0}$, the turbulent Prandtl number $\operatorname{Pr}_{\mathrm{t}}=0.75$, and $\zeta(\xi, \mathrm{H})$ is given by the second Eq. (16).

The projections of the momentum balance equation (5)-(7) can be transformed to the following dimensionless form (where some of the minor terms are omitted)

$$
\begin{aligned}
& \frac{\partial^{2} \xi}{\partial \mathrm{t}^{2}}=\frac{2}{\operatorname{Re}} \Phi \frac{\partial^{2} \xi}{\partial \mathrm{s}^{2}}+\frac{\tau_{\xi}}{\mathrm{Fr}^{2}}+\ell \mathrm{J} \frac{\mathrm{q}_{\mathrm{total}, \tau}}{\mathrm{f}} \\
& \frac{\partial^{2} \mathrm{H}}{\partial \mathrm{t}^{2}}=\left[\frac{\tau_{\tau \tau}}{\operatorname{Re}}-\mathrm{J} \varphi^{2} \xi, \mathrm{H}, \mathrm{Z}\right]\left|\mathrm{b}_{\zeta}\right| \frac{1}{\lambda^{2}} \frac{\partial^{2} \mathrm{H}}{\partial \mathrm{s}^{2}}-\frac{\tau_{\eta}}{\operatorname{Fr}^{2}}+\mathrm{b}_{\zeta} \ell \mathrm{J} \frac{\varphi^{2} \xi, \mathrm{H}, \mathrm{Z}}{\pi \mathrm{a}} \mathrm{n}_{\xi}^{2} \operatorname{sign}\left(\mathrm{n}_{\xi}\right) \\
& \frac{\partial^{2} \mathrm{Z}}{\partial \mathrm{t}^{2}}=\left[\frac{\tau_{\tau \tau}}{\operatorname{Re}}-\mathrm{J} \varphi^{2} \xi, \mathrm{H}, \mathrm{Z}\right]\left|\mathrm{b}_{\eta}\right| \frac{1}{\lambda^{2}} \frac{\partial^{2} \mathrm{Z}}{\partial \mathrm{s}^{2}}+\frac{\mathrm{b}_{\eta} \tau_{\eta}+\mathrm{b}_{\xi}}{\mathrm{b}_{\eta} \mathrm{Fr}^{2}}-\mathrm{b}_{\eta} \ell \mathrm{J} \frac{\varphi^{2} \xi, \mathrm{H}, \mathrm{Z}}{\pi \mathrm{a}} \mathrm{n}_{\xi}^{2} \operatorname{sign}\left(\mathrm{n}_{\xi}\right)
\end{aligned}
$$

where

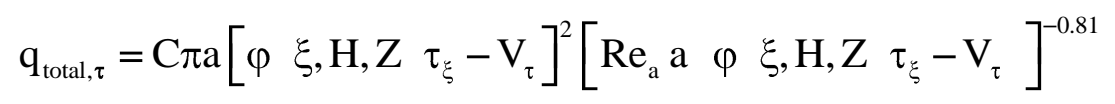


$\tau_{\xi}=\frac{\xi_{, s}}{\lambda}, \tau_{\eta}=\frac{H_{s}}{\lambda}, \tau_{\zeta}=\frac{Z_{, s}}{\lambda}$

$\mathrm{n}_{\xi}=\frac{\xi_{, \mathrm{ss}} \mathrm{H}_{, \mathrm{s}}^{2}+\mathrm{Z}_{, \mathrm{s}}^{2}-\xi_{, \mathrm{s}} \mathrm{H}_{\mathrm{ss}} \mathrm{H}_{\mathrm{s}}+\mathrm{Z}_{\mathrm{ss}} \mathrm{Z}_{, \mathrm{s}}}{\lambda \sqrt{\mathrm{Z}_{\mathrm{ss}} \mathrm{H}_{, \mathrm{s}}-\mathrm{H}_{\mathrm{ss}} \mathrm{Z}_{, \mathrm{s}}{ }^{2}+\xi_{, \mathrm{ss}} \mathrm{Z}_{, \mathrm{s}}-\mathrm{Z}_{\mathrm{ss}} \xi_{\mathrm{s}}{ }^{2}+\mathrm{H}_{\mathrm{ss}} \xi_{, \mathrm{s}}-\xi_{, \mathrm{ss}} \mathrm{H}_{\mathrm{s}}{ }^{2}}}$,

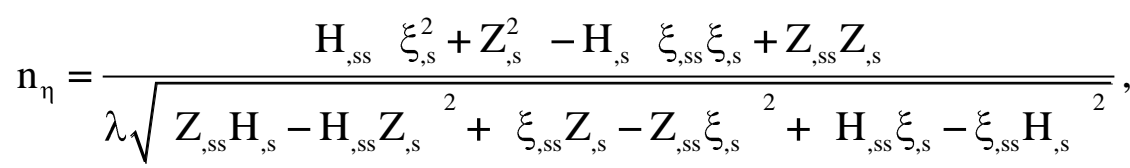

$\mathrm{n}_{\zeta}=\frac{\mathrm{Z}_{\mathrm{ss}} \xi_{, \mathrm{s}}^{2}+\mathrm{H}_{\mathrm{s}}^{2}-\mathrm{Z}_{\mathrm{s}} \xi_{, \mathrm{ss}} \xi_{\mathrm{s}}+\mathrm{H}_{\mathrm{ss}} \mathrm{H}_{\mathrm{s}}}{\lambda \sqrt{\mathrm{Z}_{\mathrm{ss}} \mathrm{H}_{\mathrm{s}}-\mathrm{H}_{\mathrm{ss}} \mathrm{Z}_{\mathrm{s}}^{2}+\xi_{, \mathrm{ss}} \mathrm{Z}_{\mathrm{s}}-\mathrm{Z}_{\mathrm{ss}} \xi_{, \mathrm{s}}^{2}+\mathrm{H}_{\mathrm{ss}} \xi_{, \mathrm{s}}-\xi_{, \mathrm{ss}} \mathrm{H}_{, \mathrm{s}}{ }^{2}}}$

$\mathrm{b}_{\xi}=\tau_{\eta} \mathrm{n}_{\zeta}-\mathrm{n}_{\eta} \tau_{\zeta}, \quad \mathrm{b}_{\eta}=\tau_{\zeta} \mathrm{n}_{\xi}-\mathrm{n}_{\zeta} \tau_{\xi}, \quad \mathrm{b}_{\zeta}=\tau_{\xi} \mathrm{n}_{\eta}-\mathrm{n}_{\xi} \tau_{\eta}$

$\operatorname{Re}=\frac{\rho L U_{g} 0}{\mu_{0}}, \quad J=\frac{\rho_{\mathrm{g}}}{\rho}, \quad F r=\left(\frac{\mathrm{U}_{\mathrm{g} 0}^{2}}{\mathrm{gL}}\right)^{1 / 2}, \quad \operatorname{Re}_{\mathrm{a}}=\frac{2 \mathrm{a}_{0, \text { straight }} \mathrm{U}_{\mathrm{g} 0}}{v_{\mathrm{g}}}$

$\mathrm{Re}$ and $\mathrm{Re}_{\mathrm{a}}$ denote the corresponding Reynolds numbers, Fr is the Froude number.

Following Refs. 4 and 5, the boundary conditions for Eqs. (25)-(27) at the end of the straight part correspond to the overall effect of turbulent eddies expressed as

$\xi_{\text {origin }} \approx 0, \mathrm{H}_{\text {origin }}=\mathrm{H}_{\mathrm{j}}+\mathrm{H}_{0 \Omega} \sin \left(\Omega_{\mathrm{j}} \mathrm{t}\right), \mathrm{Z}_{\text {origin }}=\mathrm{H}_{0 \Omega} \cos \left(\Omega_{\mathrm{j}} \mathrm{t}\right)$

where $\mathrm{H}_{\mathrm{j}}$ were constants monotonously increasing from jet to jet, which corresponds to the nosepiece with the die exits located in the $\mathrm{H}$ direction.

In Eqs. (35)

$$
\mathrm{H}_{0 \Omega}=0.06 \mathrm{Re}^{1 / 2} / \ell^{1 / 2} / \tau_{\tau \tau 0}^{1 / 4}, \quad \Omega_{\mathrm{j}}=\frac{\omega_{\mathrm{j}} \mathrm{L}}{\mathrm{U}_{\mathrm{g} 0}}
$$

where the dimensionless (and the corresponding dimensional) frequencies $\Omega_{\mathrm{j}}$ (and $\omega_{\mathrm{j}}$ ) were chosen randomly from jet to jet, as described in section III. 
In Eq. (36), $\tau_{\tau \tau 0}$ is related to the dimensionless longitudinal stress at the end of the straight part of the jet predicted in section II, as discussed in section III.

The free end of the jet is practically unloaded, which corresponds to

$$
\left.\xi_{, \mathrm{s}}\right|_{\mathrm{s}=\mathrm{end}}=1,\left.\quad \mathrm{H}_{\mathrm{s}}\right|_{\mathrm{s}=\mathrm{end}}=0 \text { and }\left.\quad \mathrm{Z}_{\mathrm{s}}\right|_{\mathrm{s}=\mathrm{end}}=0
$$

On the other hand, when a material point of a jet touches the screen moving in the $\mathbf{Z}$-direction, its $\xi$ coordinate stays "frozen" at $\xi=1$, the $\mathrm{H}$ coordinate stays "frozen" at the value it has had at the moment of touching the screen, while its $\mathrm{Z}$ coordinate increases as

$$
\mathrm{Z}=\mathrm{Z}_{\text {touch }}+\mathrm{V}_{\text {screen }} \mathrm{t}
$$

The initial condition for Eq. (22) at the moment when a liquid element enters the bending part of the jet $t_{\text {birth }}$ reads

$$
\left.\phi\right|_{\mathrm{t}=\mathrm{t}_{\text {birth }}}=\tau_{\tau \tau 0}+\mathrm{T}_{0} / \mathrm{De}_{0} / \lambda_{0}^{2}
$$




\section{References}

[1] Marla VT, Shambaugh RL. Three-dimensional model of melt-blowing process. Industrial \& Engineering Chemistry Research. 2003; 42: 6993-7005.

[2] Pinchuk LC, Goldade VA, Makarevich AV, Kestelman VN. Meltblowing, Equipment, Technology and Polymer Fibrous Materials, Springer, Berlin, 2002.

[3] Medeiros ES, Glenn GM, Klamczynski AP, Orts WJ, Mattoso LHC. Solution blow spinning: A new method to produce micro- and nanofibers from polymer solutions. Journal of Applied Polymer Science. 2009 ; 113 : 2322- 30 .

[4] Sinha-Ray S, Yarin AL, Pourdeyhimi B. Meltblowing: I-Basic physical mechanisms and threadline model. Journal of Applied Physics. 2010; 108: 034912.

[5] Yarin AL, Sinha-Ray S, Pourdeyhimi B. Meltblowing: II-Linear and nonlinear waves on viscoelastic polymer jets. Journal of Applied Physics. 2010; 108: 034913.

[6] Reneker DH, Yarin AL, Fong H, Koombhongse S. Bending instability of electrically charged liquid jets of polymer solutions in electrospinning. Journal of Applied Physics. 2000 ; 87: 4531-47.

[7] Ziabicki A, Kawai H (Editors). High-Speed Fiber Spinning. Wiley, New York, 1985.

[8] Yarin AL. Free Liquid Jets and Films: Hydrodynamics and Rheology. Longman, Harlow and Wiley\&Sons, New York, 1993.

[9] Doi M. Molecular rheology of concentrated polymer systems. Journal of Polymer Science, Polym. Phys. Ed. 1980; 18: 1005-20. 
[10] Breese RR, Ko WC. Fiber formation during melt blowing. International Nonwovens Journal; 2003 Summer, 21-28.

[11] Shambaugh RL. A macroscopic view of the melt-blowing process for producing microfibers. Industrial \& Engineering Chemistry Research.1988; 27: 2363-72.

[12] Yarin AL. Self-similarity. Section 2.3 in Springer Handbook of Experimental Fluid Mechanics (Eds. Tropea, C, Yarin, AL, Foss, J), pp. 57-82, Springer, Berlin, 2007.

[13] Breese RR, Qureshi UA. Influence of process conditions on melt blown web structure. Part IV - Fiber Diameter. Journal of Engineered Fibers and Fabrics. 2006; 1:32-46.

[14] Rawal A, Priyadarshi A, Lomov SV, Verpoest I, Vankerrebrouck J. Tensile behaviour of thermally bonded nonwoven structures: model description. J. Mater. Sci. 2010; 45: 2274-2284.

[15] Begenir A. Structure-process-property relationships in elastic nonwovens made from multi-block elastomers (PhD Thesis). Fiber and Polymer Science, North Carolina State University, 2008.

[16] Yarin AL, Koombhongse S, Reneker DH. Bending instability in electrospinning of nanofibers. Journal of Applied Physics. 2001; 89: 3018-26.

[17] Thompson CJ, Chase GG, Yarin AL, Reneker DH. Effect of parameters on nanofiber diameter determined from electrospinning model. Polymer. 2007; 48: 6913-22. 